\title{
17
}

\section{Growth, energy use and greenhouse gas emissions in China}

\author{
Warwick J. McKibbin
}

Energy is a key issue for the Chinese economy, now and in future decades. The need for expanding sources of energy as an input into a rapidly growing economy and the environmental implications of rising energy use are well understood within China. Chinese energy use is also becoming an increasingly important issue for the global economy because of the scale of China's energy requirements and because of the implications for global climate change of quickly rising greenhouse emissions from China.

With roughly 20 per cent of the world's population and economic growth in the range of 10 per cent per annum, China is already having a significant impact on global energy demand. By 2002, China was the world's third largest energy producer and the second largest energy consumer. ${ }^{1}$ Although China has large reserves of energy and rising capacity it shifted from being a net energy exporter to a net energy importer in 1998 (Figure 17.1). This massive increase in the use of energy has had important implications for local environmental problems such as air quality, public health problems and local climate change. Energy generation and its related emissions of sulphur dioxide from coal use, has caused local and regional problems with acid rain. ${ }^{2}$ The large and growing emissions of greenhouse gases (particularly carbon dioxide emissions from burning coal) are a critical input into the global issue of climate change. ${ }^{3}$

In 1990 China accounted for 7.8 per cent of world energy use, which was roughly 1.5 times the energy use of Japan and seven times that of South Korea (Table 17.1). By 2002, China's share of global energy use had risen to 10.3 per cent. The 
Figure 17.1 China's total energy consumption and supply, 1980-2003 (quadrillion Btu)

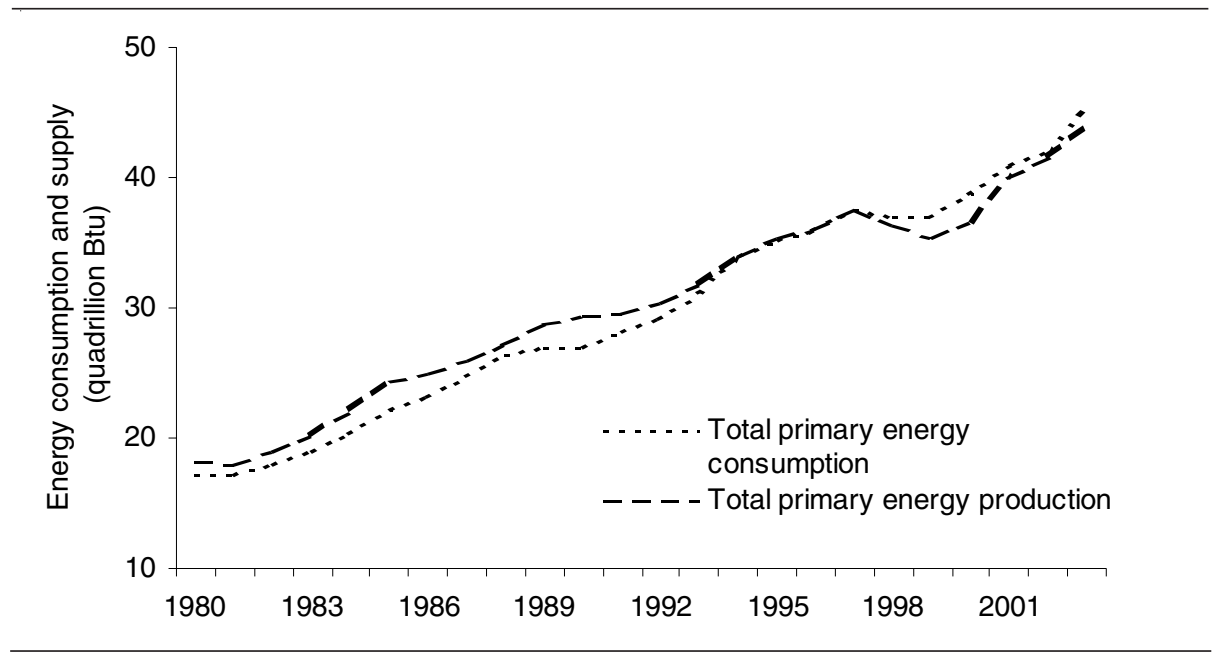

Source: Energy Information Agency, 2006b. International Energy Outlook 2006, Department of Energy, Washington, DC.

\section{Table 17.1 China's share of global energy consumption and carbon dioxide emissions, 1990-2030}

\begin{tabular}{|c|c|c|c|c|c|c|c|c|}
\hline \multicolumn{9}{|c|}{ Energy consumption } \\
\hline & 1990 & 2002 & 2003 & 2010 & 2015 & 2020 & 2025 & 2030 \\
\hline China & 7.8 & 10.3 & 10.8 & 15.1 & 16.3 & 17.4 & 18.3 & 19.3 \\
\hline India & 2.3 & 3.4 & 3.3 & 3.8 & 4.0 & 4.2 & 4.4 & 4.5 \\
\hline \multicolumn{2}{|c|}{ Other non-OECD33.1 } & 29.9 & 30.2 & 30.8 & 31.8 & 32.5 & 33.1 & 33.4 \\
\hline South Korea & 1.1 & 2.0 & 2.0 & 2.1 & 2.2 & 2.2 & 2.2 & 2.1 \\
\hline Japan & 5.3 & 5.4 & 5.3 & 4.5 & 4.2 & 3.8 & 3.6 & 3.4 \\
\hline United States & 24.4 & 23.9 & 23.3 & 21.2 & 20.3 & 19.7 & 19.1 & 18.6 \\
\hline Other OECD & 26.1 & 25.2 & 25.0 & 22.5 & 21.3 & 20.2 & 19.4 & 18.7 \\
\hline World total & 100.0 & 100.0 & 100.0 & 100.0 & 100.0 & 100.0 & 100.0 & 100.0 \\
\hline \multicolumn{9}{|l|}{$\mathrm{CO}_{2}$ emissions } \\
\hline China & 10.6 & 13.5 & 14.1 & 19.3 & 20.8 & 22.2 & 23.3 & 24.5 \\
\hline India & 2.7 & 4.2 & 4.1 & 4.5 & 4.7 & 4.9 & 5.0 & 5.0 \\
\hline \multicolumn{2}{|c|}{ Other non-OECD33.1 } & 29.1 & 29.2 & 29.3 & 29.9 & 30.2 & 30.3 & 30.4 \\
\hline South Korea & 1.1 & 1.9 & 1.9 & 2.0 & 2.0 & 2.0 & 2.0 & 1.9 \\
\hline Japan & 4.8 & 4.9 & 4.8 & 4.0 & 3.6 & 3.3 & 3.0 & 2.8 \\
\hline United States & 23.5 & 23.6 & 23.2 & 21.0 & 20.0 & 19.4 & 18.9 & 18.6 \\
\hline Other OECD & 24.3 & 22.8 & 22.7 & 20.0 & 19.0 & 18.1 & 17.4 & 16.8 \\
\hline World total & 100.0 & 100.0 & 100.0 & 100.0 & 100.0 & 100.0 & 100.0 & 100.0 \\
\hline
\end{tabular}

Source: Energy Information Agency, 2006b. International Energy Outlook 2006, Department of Energy, Washington DC. 
United States Energy Information Administration predicts that by 2030, China will account for more than 19 per cent of global energy use, or more than five times the energy use of Japan and nine times that of South Korea. China is already the world's largest coal producer, accounting for 28 per cent of world coal production and 27 per cent of world coal consumption by 2002 (Table 17.2). China's share of world coal consumption is projected to rise to a massive 44 per cent by 2030 (Table 17.2), and at the time will be more than 2.5 times the coal consumption of the United States. China's share of world oil consumption in 1990 was 3.5 per cent, but it is projected to rise to 12.7 per cent by 2030 (Table 17.2).

Until recently, the focus of policy in China has been on sustaining economic growth and energy needs rather than the environmental consequences of rapid industrialisation. This is beginning to change as rising income levels in China make the environment a more important issue and as environmental quality continues to deteriorate.

This chapter summarises the recent history of energy use in China and presents some estimates of future projections of energy use. Although there is a range of environmental issues associated with energy, this chapter focuses primarily on the emissions of carbon dioxide-a critical driver of global climate change. ${ }^{4}$ Although economic growth is still a priority in China, environmental policy is emerging as an important issue. ${ }^{5}$ Indeed, China has shown a commitment to tackle local environmental problems with encouraging outcomes. ${ }^{6}$ For example, Jiang and McKibbin (2002) find that Chinese policy has been effective in reducing environmental problems in a number of areas, relative to what otherwise would be the case. However, many environmental problems continue to worsen despite policy intervention, due to other factors driven by strong economic growth.

The remainder of this chapter is structured as follows. The second section presents a brief overview of energy use and carbon dioxide emissions in China. It also summarises projections from the United States Energy Information Administration's International Energy Outlook (2006b) of energy use and carbon dioxide emissions in China until 2030. The third section summarises the current policy debate on climate change and the implications for future Chinese energy. The fourth section focuses on the sensitivity of projections of energy use and carbon dioxide emissions to assumptions about the sources of economic growth. This analysis is based on projections from the G-cubed multi-country model under different assumptions about the sources of economic growth in China. Finally, the sensitivity of projections to the price of carbon is assessed in the fifth section. A conclusion appears in the final section. Appendix Table A17.1 summarises the G-cubed multicountry model that forms the basis of some of the analysis in this paper. 
The Turning Point in China's Economic Development

\section{Energy use and carbon dioxide emissions in China}

\section{History}

The importance of China in world energy use and the projected increases in this importance are summarised in Table 17.1. In 2003, China accounted for 10.8 per cent of world energy use (compared with the United States at 23.3 per cent) and 14.1 per cent of global carbon dioxide emissions from fossil fuel use (compared with the United States at 23.3 per cent). Chinese GDP (in 2003) was estimated in PPP terms to be roughly 59 per cent of the size of that of the United States. ${ }^{7}$ This implies that although carbon emissions per unit of energy use are higher in China than in the United States, energy use per unit of GDP (in PPP terms) is slightly lower in China than in the United States.

China has roughly 9.4 per cent of the world's installed electricity generation capacity (second only to the United States) and in the next three decades it is predicted to be responsible for up to 25 per cent of the increase in global energy generation. China's size and the composition of its energy use, with a large reliance on coal, are reflected in carbon dioxide emissions. China is estimated to have emitted 14.1 per cent of global carbon emissions from fossil fuels in 2003 (second only to the United States in terms of individual countries) and this share is projected to rise to $24.5 \mathrm{per}$ cent by 2030 (Table 17.1). In an attempt to move away from reliance on fossil fuels, China has plans for another 30 nuclear power plants in the next two decades to supplement its nine existing nuclear reactors. ${ }^{8}$ It is estimated that China has the largest hydroelectric capacity in the world (largely in the southwest of the country), currently generating 20 per cent of Chinese electricity. The Three Gorges hydroelectric dam on the Yangtze River will be the world's largest power plant when completed about 2009. The National Development and Reform Commission (NDRC) approved the largest wind farm in Asia in March 2005, to begin construction in 2006. There is projected to be a rapidly rising share of nuclear energy and renewable energy (particularly hydro) in Chinese energy production in coming years (Table 17.3). Despite the impressive scale of this expansion, the emergence of renewable energy will dent only slightly the overall dominance of coal in the foreseeable future in China, at least under current relative energy prices. The large rise in coal as a source of primary energy implies that China will need to respond to a range of environmental problems resulting from burning fossil fuels, including air quality (including black carbon emissions), acid rain (from emissions of sulphur dioxide and nitrogen oxides) and climate change (from carbon dioxide emissions).

Figure 17.1 gives another perspective on the recent history of energy production and consumption in China. Energy demand and supply in China has been rising 
quickly—more than doubling between 1980 and 1996. In 1998, Chinese energy consumption began to outstrip production, with China becoming a net energy importer.

Figure 17.2 shows that an abundance of low-cost coal has been the predominant source of Chinese energy supply (located mainly in the northern part of the country). Crude oil (petroleum) is the next largest source of energy supply, followed by hydroelectricity, natural gas and nuclear energy. The major source of demand for energy in China ${ }^{9}$ is industry, which accounted for 68.9 per cent of the total in 2002.

\section{Table 17.2 China's shares of global consumption of fossil fuel energy components, 1990-2030 (per cent)}

\begin{tabular}{|c|c|c|c|c|c|c|c|c|}
\hline & 1990 & 2002 & 2003 & 2010 & 2015 & 2020 & 2025 & 2030 \\
\hline \multicolumn{9}{|c|}{ Coal consumption } \\
\hline China & 21.3 & 26.9 & 28.1 & 36.4 & 39.1 & 40.8 & 42.3 & 44.0 \\
\hline India & 4.9 & 8.2 & 7.9 & 8.4 & 8.8 & 9.0 & 8.8 & 8.4 \\
\hline Other non-OECL & D 25.4 & 18.4 & 18.4 & 16.6 & 16.5 & 16.2 & 15.7 & 15.1 \\
\hline South Korea & 0.9 & 1.5 & 1.5 & 1.7 & 1.7 & 1.6 & 1.7 & 1.7 \\
\hline Japan & 2.4 & 3.3 & 3.2 & 2.5 & 2.3 & 2.0 & 1.8 & 1.6 \\
\hline United States & 17.2 & 20.3 & 20.1 & 17.7 & 16.4 & 16.1 & 16.7 & 16.9 \\
\hline Other OECD & 28.0 & 21.4 & 20.7 & 16.5 & 15.2 & 14.2 & 13.1 & 12.4 \\
\hline World total & 100.0 & 100.0 & 100.0 & 100.0 & 100.0 & 100.0 & 100.0 & 100.0 \\
\hline \multicolumn{9}{|c|}{ Oil consumption } \\
\hline China & 3.5 & 6.6 & 7.0 & 9.5 & 10.2 & 11.2 & 11.9 & 12.7 \\
\hline India & 1.8 & 2.9 & 2.9 & 3.2 & 3.4 & 3.6 & 3.7 & 3.8 \\
\hline Other non-OECL & D 32.7 & 29.6 & 29.6 & 30.9 & 31.7 & 32.0 & 32.5 & 32.8 \\
\hline South Korea & 1.5 & 2.7 & 2.7 & 2.8 & 3.0 & 2.9 & 2.9 & 3.0 \\
\hline Japan & 7.8 & 7.0 & 7.0 & 5.9 & 5.6 & 5.2 & 5.0 & 4.6 \\
\hline United States & 25.5 & 25.2 & 25.1 & 24.2 & 23.9 & 23.8 & 23.6 & 23.4 \\
\hline Other OECD & 27.2 & 25.9 & 25.7 & 23.5 & 22.4 & 21.2 & 20.4 & 19.7 \\
\hline World total & 100.0 & 100.0 & 100.0 & 100.0 & 100.0 & 100.0 & 100.0 & 100.0 \\
\hline \multicolumn{9}{|c|}{ Natural gas consumption } \\
\hline China & 0.7 & 1.2 & 1.3 & 2.6 & 2.9 & 3.4 & 3.7 & 3.8 \\
\hline India & 0.5 & 1.0 & 1.0 & 1.3 & 1.3 & 1.5 & 1.9 & 2.5 \\
\hline Other non-OECL & D 48.5 & 44.2 & 45.1 & 48.0 & 49.3 & 50.6 & 51.7 & 52.9 \\
\hline South Korea & 0.1 & 0.9 & 0.9 & 0.9 & 0.9 & 0.9 & 0.8 & 0.7 \\
\hline Japan & 2.6 & 3.1 & 3.2 & 2.7 & 2.6 & 2.4 & 2.2 & 2.1 \\
\hline United States & 26.2 & 24.9 & 23.4 & 20.1 & 19.3 & 17.9 & 16.3 & 14.8 \\
\hline Other OECD & 21.3 & 24.8 & 25.0 & 24.5 & 23.8 & 23.3 & 23.3 & 23.2 \\
\hline World total & 100.0 & 100.0 & 100.0 & 100.0 & 100.0 & 100.0 & 100.0 & 100.0 \\
\hline
\end{tabular}

Source: Energy Information Agency, 2006b. International Energy Outlook 2006, Department of Energy, Washington DC. 


\begin{tabular}{|c|c|c|c|c|c|c|c|c|}
\hline \multirow[t]{2}{*}{ Table 17.3} & \multicolumn{8}{|c|}{$\begin{array}{l}\text { Shares in global consumption of non-fossil fuel energy } \\
\text { components, 1990-2030 (per cent) }\end{array}$} \\
\hline & 1990 & 2002 & 2003 & 2010 & 2015 & 2020 & 2025 & 2030 \\
\hline \multicolumn{9}{|c|}{ Nuclear energy consumption } \\
\hline China & 0.0 & 1.0 & 1.7 & 2.9 & 4.4 & 5.5 & 7.1 & 9.2 \\
\hline India & 0.3 & 0.7 & 0.6 & 2.0 & 2.6 & 3.2 & 3.3 & 3.4 \\
\hline Other non-OECl & D 14.0 & 12.8 & 13.1 & 13.5 & 15.0 & 17.0 & 18.3 & 17.5 \\
\hline South Korea & 2.6 & 4.4 & 4.9 & 5.2 & 6.0 & 6.4 & 6.7 & 7.2 \\
\hline Japan & 10.1 & 11.0 & 9.4 & 10.0 & 9.8 & 10.2 & 10.8 & 11.2 \\
\hline United States & 30.2 & 30.6 & 30.3 & 29.5 & 28.2 & 27.9 & 26.9 & 26.4 \\
\hline Other OECD & 42.7 & 39.5 & 40.1 & 36.8 & 34.0 & 29.8 & 36.8 & 25.0 \\
\hline World total & 100.0 & 100.0 & 100.0 & 100.0 & 100.0 & 100.0 & 100.0 & 100.0 \\
\hline \multicolumn{9}{|c|}{ Hydroelectricity and other renewable energy consumption } \\
\hline China & 4.9 & 8.7 & 8.9 & 13.5 & 13.8 & 13.4 & 12.6 & 12.2 \\
\hline India & 2.7 & 2.2 & 2.1 & 2.9 & 2.6 & 2.8 & 3.1 & 3.5 \\
\hline Other non-OECl & D 31.6 & 34.5 & 35.5 & 35.8 & 38.1 & 39.5 & 41.5 & 43.1 \\
\hline South Korea & 0.0 & 0.0 & 0.3 & 0.4 & 0.6 & 0.6 & 0.5 & 0.5 \\
\hline Japan & 4.2 & 3.4 & 4.3 & 3.1 & 3.1 & 2.8 & 2.6 & 2.6 \\
\hline United States & 23.2 & 18.3 & 17.4 & 15.9 & 15.3 & 15.3 & 15.1 & 14.6 \\
\hline Other OECD & 33.1 & 32.9 & 31.2 & 28.5 & 26.5 & 25.6 & 24.6 & 23.6 \\
\hline World total & 100.0 & 100.0 & 100.0 & 100.0 & 100.0 & 100.0 & 100.0 & 100.0 \\
\hline
\end{tabular}

Source: Energy Information Agency, 2006b. International Energy Outlook 2006, Department of Energy, Washington DC.

This is followed by the household sector at 11.4 per cent and transportation at only 7.5 per cent.

\section{Projections}

Projecting future energy use in China, especially over horizons of more than a decade, is very difficult. It is tempting to base future projections on extrapolations of recent trends; however, as shown by Bagnoli et al. (1996) and McKibbin et al. (2004), overall economic growth need not be the key determinant of energy use. The sources of economic growth are critical. A number of projections are available publicly. The Energy Information Administration of the United States Department of Energy, in its annual International Energy Outlook (2006b), provides one source of projections. Projections for Chinese energy consumption in quadrillion BTU are shown in Figure 17.3 for three scenarios: high and low economic growth and a reference case.

Figure 17.4 shows the Energy Information Administration's projections for carbon dioxide emissions by energy source in China for the reference case scenario. It is 
Figure 17.2 Energy consumption by source in China, 1980-2003 (quadrillion Btu)

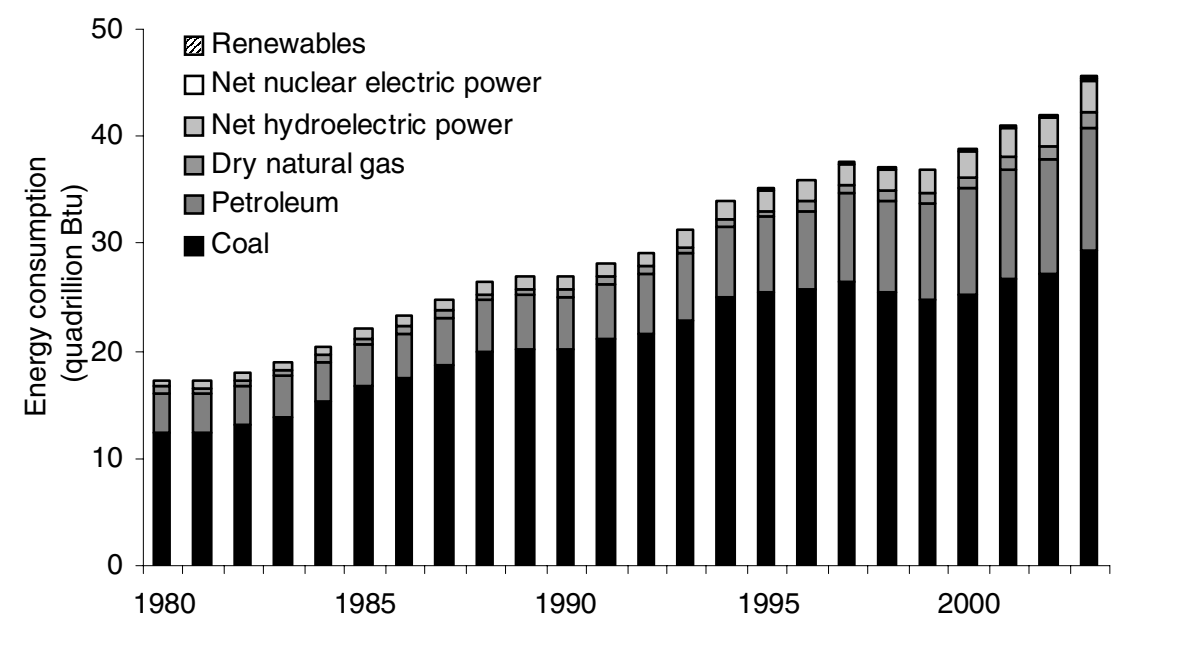

Source: Energy Information Agency, 2006b. International Energy Outlook 2006, Department of Energy, Washington, DC.

clear that coal burning is the overwhelming source of carbon dioxide emissions in China historically, and in these projections it is expected to be the major source of energy and therefore emissions in the foreseeable future. This is not surprising given the large quantity of low-cost coal available in China and the assumptions of unchanging relative energy prices in these projections. Over time, the share of emissions from petroleum is projected to rise as greater use of motor vehicles and other non-stationary energy uses rise. It will be shown in the next section that these types of projections are contingent on assumptions about the price of energy relative to other goods and the relative price of alternative energy sources.

Figure 17.5 shows the global sources of carbon dioxide from burning fossil fuels, by region, in 1990 and those projected for 2030 in the 2006 International Energy Outlook. Not only is China currently an important source of carbon dioxide emissions, its share is expected to grow quickly. Its absolute size (Figure 17.5) and its share of global emissions (Table 17.1), suggest that China is a critical country in the debate over policies to deal with potential climate change. These projections assume business as usual, and therefore incorporate global Kyoto Protocol commitments. 
The Turning Point in China's Economic Development

Figure 17.3 Projections of energy consumption in China, 1990-2030 (quadrillion $\left(10^{15}\right) \mathrm{Btu}$ )

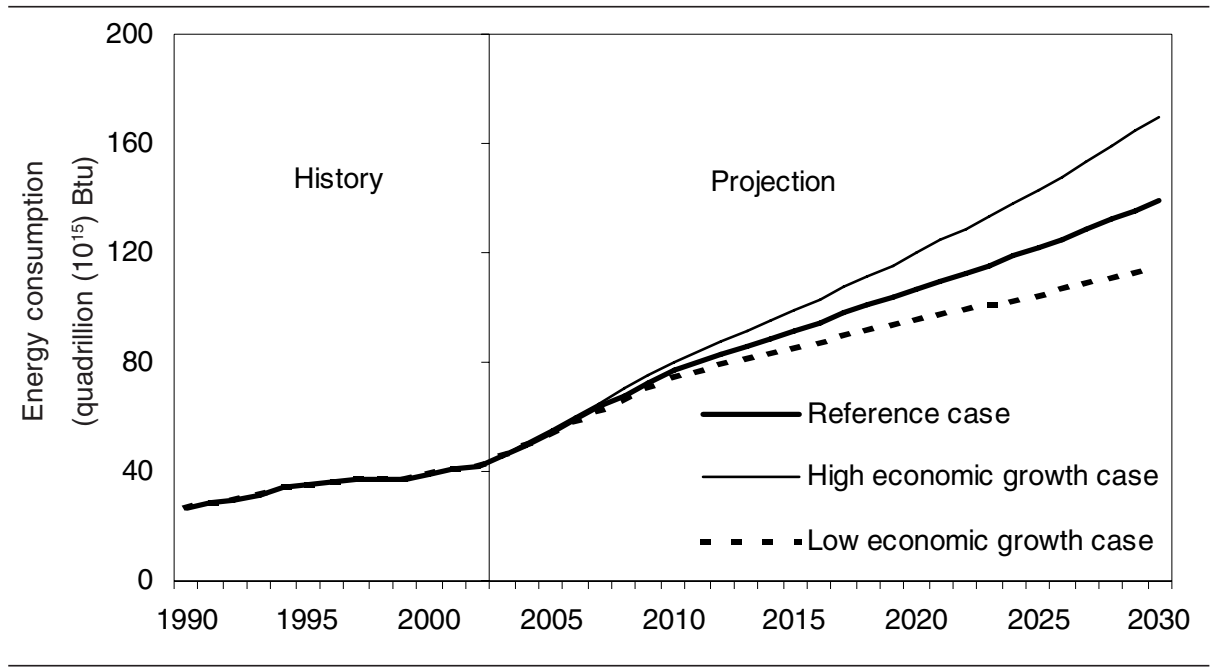

Source: Energy Information Agency, 2006b. International Energy Outlook 2006, Department of Energy, Washington, DC.

Figure 17.4 Projections of carbon dioxide emissions by fuel type in China, 1990-2030 (million metric tonnes)

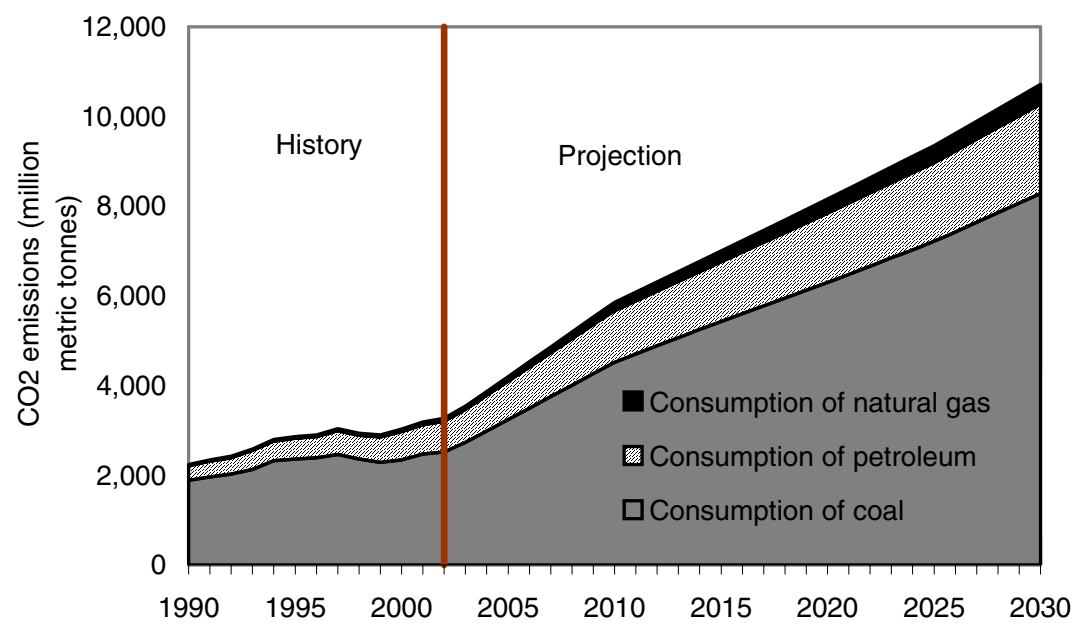

Source: Energy Information Agency, 2006b. International Energy Outlook 2006, Department of Energy, Washington, DC. 


\section{Carbon emissions and climate change}

China has begun to take action to address local environmental problems. There has been direct action to substitute non-fossil fuel energy sources such as wind, hydro and thermonuclear energy for fossil fuels in energy generation. China has also attempted to reduce the emissions of sulphur dioxide from burning fossil fuels by implementing a range of policies, from closing high-sulphur coalmines to developing markets for trading sulphur dioxide emission rights. As argued in McKibbin (2006a), a greater focus is required to address the emissions of black carbon. From a global perspective, the discussion above on future carbon emissions suggests that a critical area where China will need to take greater action is in the emissions of carbon dioxide.

The most important cause of human-induced climate change is the accumulation of greenhouse gases in the atmosphere over many decades. The most important greenhouse gas is carbon dioxide. The global community has been struggling for several decades with how to respond effectively to the threat of climate change. The United Nations Earth Summit in Rio de Janeiro in 1992 produced a landmark treaty on climate change that undertook to stabilise greenhouse gas concentrations in the atmosphere. The agreement, signed and ratified by more than 186 countries, including the United States and China (the world's largest carbon dioxide emitters), spawned numerous subsequent rounds of climate negotiations aimed at rolling back emissions from industrialised countries to the levels that prevailed in 1990 . Unfortunately, the negotiations have had little effect on greenhouse gas emissions and have not produced a detectable slowing in the rate of emissions growth. ${ }^{10}$ The treaty's implementing protocol, the 1997 Kyoto agreement, was diluted heavily at subsequent negotiations in Bonn and Marrakech. ${ }^{11}$ The Kyoto Protocol entered into force on 16 February 2005 after ratification by Russia, yet there are still many problems to be faced before it will be evident that Kyoto is reducing emissions. More than a decade of negotiations has produced a policy that is likely to be ineffective in practice.

The difficulty at the international level is worse than it appears from the troubled process of Kyoto ratification. The Kyoto Protocol places restrictions only on industrial economies, excluding the world's largest greenhouse emitter, the United States. Developing countries, including China, have ratified the agreement but have not taken on any responsibilities for reducing emissions except those that emerge from mechanisms such as the Clean Development Mechanism (CDM) and joint implementation. That developing countries are not taking on targets as commitments is one of the reasons given by the United States and Australia for 
Figure 17.5 Global carbon dioxide emissions from fossil fuels, 1990 and 2030 (million metric tonnes)

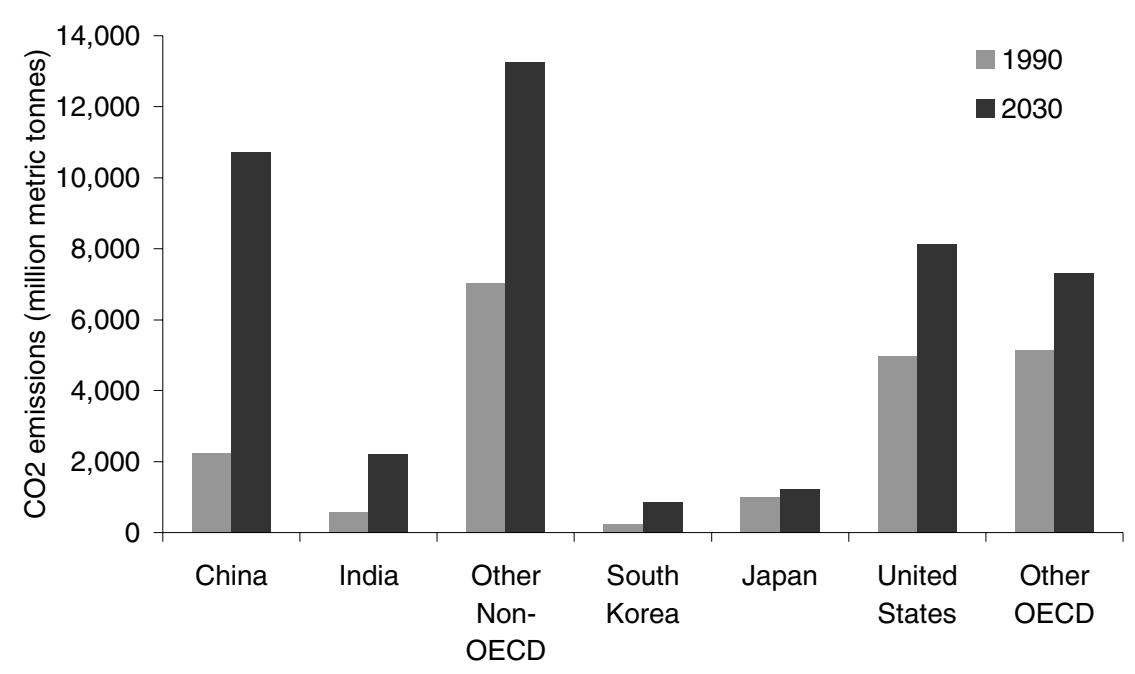

Source: Energy Information Agency, 2006b. 'Reference case', in International Energy Outlook 2006, Department of Energy, Washington, DC.

not ratifying the Kyoto Protocol. Because there have been no binding commitments by the key developing countries of China, India, Brazil and Indonesia (among others), effective action against possible climate change is still largely a hypothetical debate.

Developing countries have argued legitimately that while they are prepared to be part of a regime to tackle climate change, they should not be required to bear a disproportionate part of the costs of taking action. Current concentrations of greenhouse gases in the atmosphere are primarily the result of economic activities in the industrial economies since the Industrial Revolution. Because it is the stock of carbon in the atmosphere that matters for temperature changes, any climate change in the near future will be largely the result of the historical activities of industrial economies. One of the main dilemmas for developing countries is not just the reality that at some stage they will need to make some form of commitment to curbing greenhouse gas emissions, but the fact that most estimates of the damages from climate change are borne by developing countries. ${ }^{12}$

It is worth clarifying several important facts about the costs and benefits of climate policy and exploring whether there are approaches available to China and 
other developing countries that are being delayed by countries clinging to the Kyoto Protocol. Given the uncertainties of climate change and the decisions on energy systems being made in the rapidly growing regions of the developing world, this delay in providing clear incentives for moving away from fossil fuel-based systems might ultimately prove to be extremely costly.

Fossil fuel combustion is one of the largest sources of anthropogenic greenhouse gas emissions. Given the cost of changing existing energy systems substantially in the short term, one of the cheapest means of making the global energy system less reliant on fossil fuels is to remove these carbon emissions from future energy systems. As was shown in the second section, China is heavily reliant on coal for energy production and is likely to be so for many decades into the future. Technology will ultimately be the source of reductions in emissions, whether through the development of alternative sources of energy or through sequestration of carbon released from burning fossil fuels. Developing countries have a huge potential to avoid the pitfalls in terms of carbon intensities experienced by industrialised economies in their development process. The key issue is how to encourage the emergence of energy systems in developing countries that are less carbonintensive over time. Ultimately, if climate change does emerge as a serious problem, developing countries will have to move towards a less carbon-intensive future. It is likely to be significantly cheaper to do this over time than to face a massive restructuring at some future period-the sort of problems being faced within industrialised economies today.

The current state of global climate policy is that the United States (the largest emitter of greenhouse gases) has rejected Kyoto and is arguing for policies that directly or indirectly reduce emissions through technological change; the European Union is committed to emission targets (assuming Russia provides a great deal of the reductions required through selling emission permits) and on 1 January 2005 it implemented a Europe-wide emissions trading scheme (which exempts key sectors such as aluminium, motor vehicles and chemicals), but with caps that appear to bind only by the end of 2008; Japan is considering what it can do given current emissions are 16 per cent above targets in an economy recovering from a decade of recession; and developing countries have refused to discuss taking on commitments officially.

Given this background, there are a number of ways a country such as China could begin to address carbon emissions and make a major contribution to a global response. One policy would be to move energy prices closer to world levels by removing energy subsidies. The second would be to raise the price of energy further to reflect the true economic and environmental cost of burning fossil fuels. 
A further approach could be direct importation of less carbon-intensive technologies provided by the CDM. This latter outcome is possible but not likely, as already outlined above.

Economic theory provides guidance about the structure of a possible climate change policy for China. ${ }^{13}$ Since greenhouse gases are emitted by a vast number of highly heterogeneous sources, minimising the cost of abating a given amount of emissions requires that all sources clean up amounts that cause their marginal cost of abatement to be equated. To achieve this, the standard economic policy prescription would be a market-based instrument, such as a tax on emissions or a tradable permit system for emission rights. These types of market-based incentives for environmental pollution are already being undertaken in China through pollution charges and permit trading in sulphur dioxide. Cooper (2005) has advocated a carbon tax for China. Garbaccio et al. (1999) and McKibbin and Wilcoxen (2004) find that a price signal would be effective in changing China's future emission profiles. Given the advantages and disadvantages of the standard economic instruments, McKibbin and Wilcoxen (2002a, 2002b) show that it is possible to combine the attractive features of both systems into a single approach. They also show that it is possible to develop a system that is common in philosophy across industrialised and developing economies but in which developing economies do not incur the short-term costs to the economy in the form of higher energy prices until they have reached a capacity to pay. McKibbin and Wilcoxen (2002) have argued for a hybrid approach in which the short-term and long-term prices of carbon are changed in order to give incentives to move away from carbon-emitting energy sources. The implications of this hybrid approach for China are discussed in detail in McKibbin (2006a, 2006b).

\section{Sensitivity of energy projections to growth assumptions in China}

In this section, emission projections are presented from the G-cubed multi-country model ${ }^{14}$ to show how sensitive the projections are to assumptions about the sources of economic growth in China. Two scenarios are considered: one in which all sectors have the same productivity growth and one in which sectors experience differential productivity growth similar to the experience of the United States in the past 30 years.

A summary of the approach is provided here but further details on the technique used in the G-cubed model can be found in McKibbin et al. (2004). In the following discussion, the source of economic growth is labour-augmenting technical change and population growth. The population growth assumptions are the same across both scenarios and are based on the 2004 United Nations population projections 
(Mid scenario). In order to simplify the discussion, labour-augmenting technical change is referred to as 'productivity growth' throughout the remainder of this chapter.

In the G-cubed model, productivity growth by sector and by country is assumed to be driven by a productivity catch-up model. The United States is assumed to be the technological leader in each sector. Other countries are allocated an initial productivity gap by sector and a rate at which this gap is closed. For industrial countries and China, this is assumed to be closed at the rate of 2 per cent per annum. For other developing countries, it is assumed to be closed at 1 per cent per annum, reflecting the empirical literature. In this chapter, Chinese productivity is assumed to be 20 per cent of productivity in the equivalent sector in the United States. In the first scenario, the United States is assumed to have the same productivity growth across all sectors. This is the typical assumption in models where aggregate GDP drives energy use and therefore emissions. This scenario is labelled 'uniform productivity growth'. The implications for growth are shown in Figure 17.6. Productivity growth in all Chinese sectors is the same given the same initial gaps to the United States and the same catch-up rate across sectors.

In the second scenario, it is assumed that the differential productivity growth across sectors in the United States is similar to that experienced in the past 30 years. The growth rates are adjusted so that the aggregate GDP growth rate for

Figure 17.6 Labour-augmentative technical change for uniform productivity scenario, 2002-2100 (all sectors)

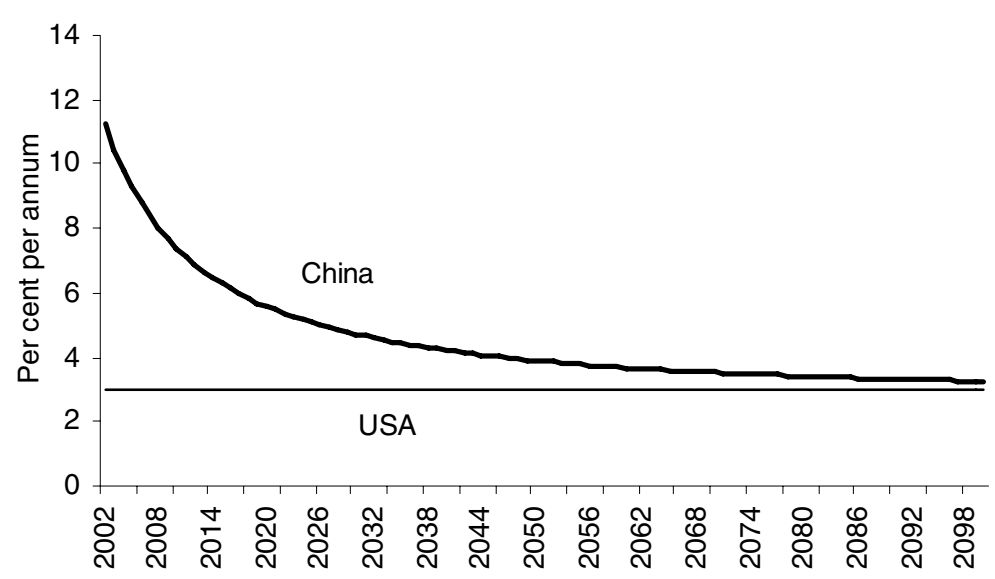

Source: G-cubed model version 63E. 
the United States is similar to GDP growth generated in the first scenario, and the main difference between the scenarios is the composition of growth. It is not possible to target GDP growth exactly.

Figures 17.6 and 17.7 show the productivity growth assumptions for each sector in the United States and the implications for the equivalent sector in China under the assumptions of the same initial gaps and rates of convergence. Although the initial productivity gaps are the same, note that in Figure 17.7, different sectors in China experience different rates of productivity growth. This is important because capital accumulation is endogenous in the G-cubed model, responding to changes in real and expected rates of return to capital.

The results from the G-cubed model for Chinese carbon dioxide emissions and GDP growth under two scenarios are shown in Figures 17.8 and 17.9 for the period from 2003 to 2030 . By 2020 , emissions under the uniform productivity scenario are 20 per cent higher than under the differential productivity growth scenario, even though GDP growth is slightly higher under the latter. Part of the difference is due to differential sectoral demand for energy as an input as well as considerably different relative energy prices under the two scenarios. These results suggest that future projections of carbon emissions and energy use in China need to be interpreted carefully.

Despite this warning on the importance of structural change in energy projections, it is difficult to see a major shift in trends away from coal under current energy prices. Interestingly, there is also little change in the real price of oil or any fossil fuels throughout the projection period in the International Energy Outlook results presented earlier, yet there are significant changes in the projections from the Gcubed model, depending on assumptions about the sources of growth.

Under most scenarios, the emergence of China as a key supplier and producer of energy is one of the most important issues in the debate over global energy use for the foreseeable future. This is also critical for environmental issues in China, Asia and globally.

\section{Sensitivity of carbon emissions to price changes}

The above scenarios considered differences in emission projections due to different growth assumptions. Due to the endogeniety of relative prices in the modelling framework used, some of the differences in energy use and emissions are due to changing relative prices due to changes in demand and supply of energy and other goods in the global economy. In this section, the focus is on the sensitivity of emission projections to relative carbon prices, by considering a carbon tax in China. 


\section{Figure 17.7 Labour-augmentative technical change by sector in differential productivity scenario, 2002-2100}

Electric utilities

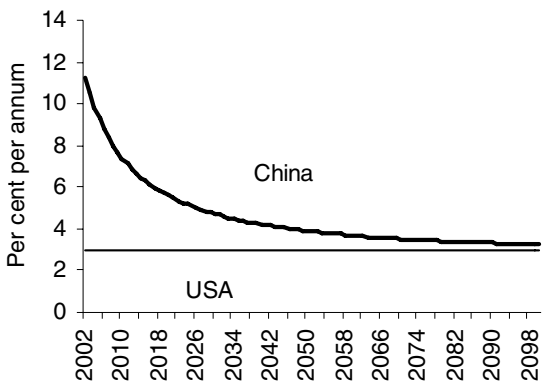

Petroleum refining

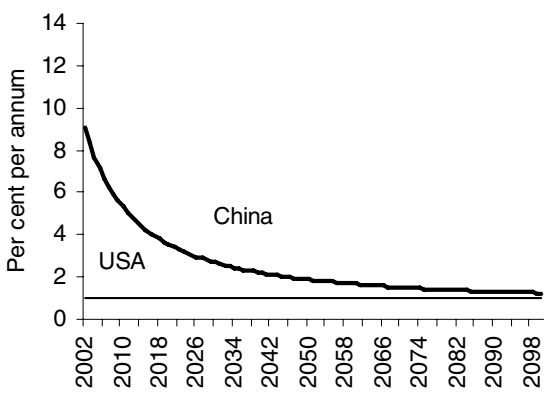

Oil and gas extraction

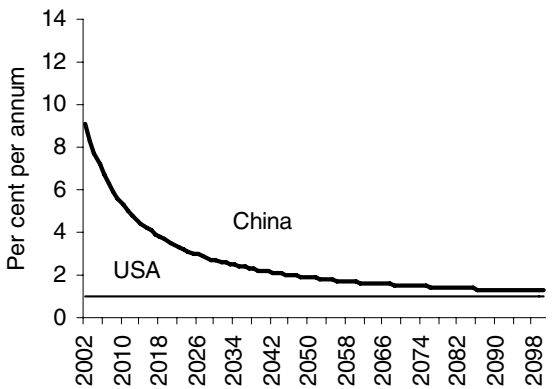

Gas utilities

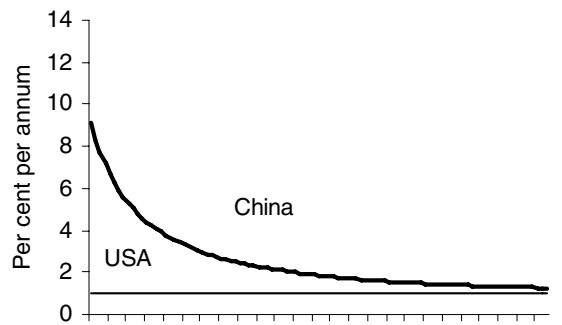

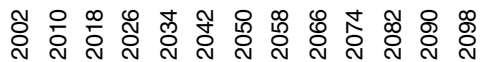

Coal mining

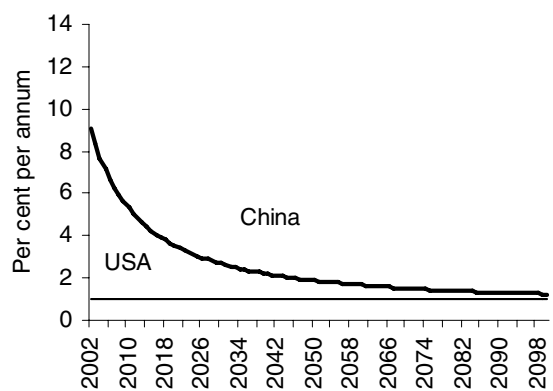

Mining

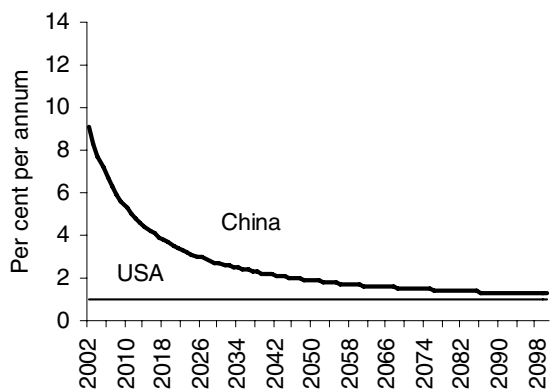

Source: G-cubed model version 63E. 


\section{Figure 17.7 Labour-augmentative technical change by sector in} differential productivity scenario, 2002-2100, continued

Agriculture

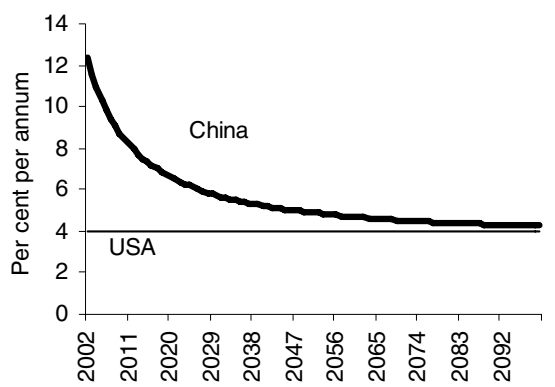

Durable manufacturing

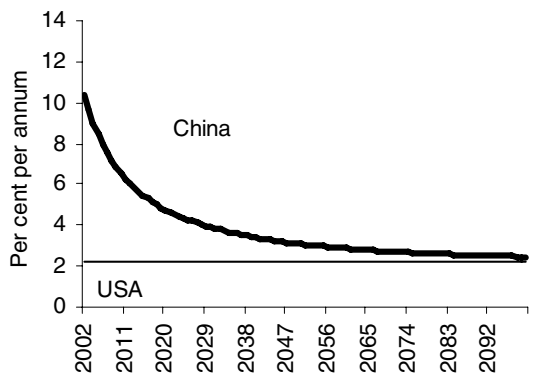

Transportation

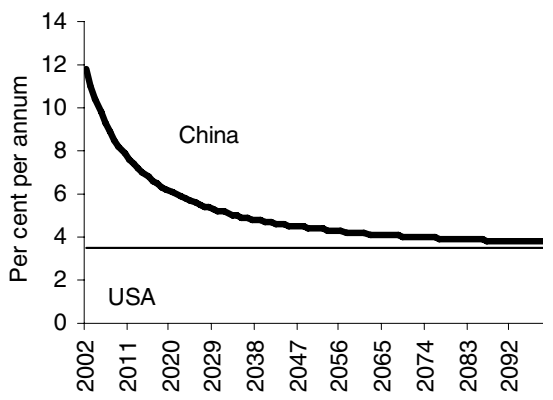

Forestry and wood products

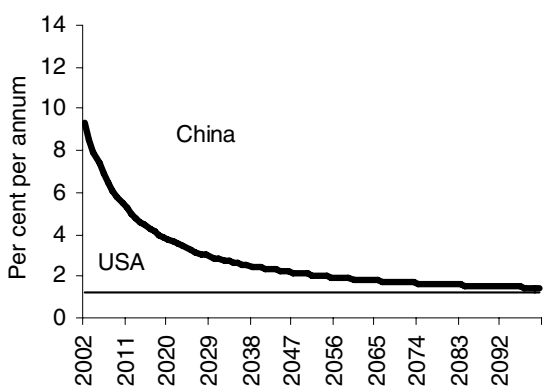

Non-durable manufacturing

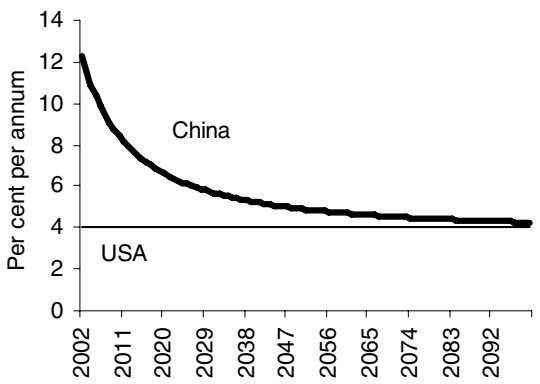

Services

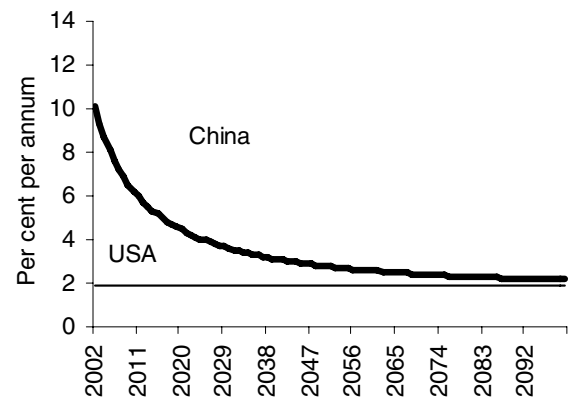

Source: G-cubed model version 63E. 
This result can also be translated approximately into the responsiveness of Chinese emissions to a conventional permit-trading system in China or a McKibbin and Wilcoxen hybrid system, except that there will be differential income and wealth effects of the latter system due to revenue going to the permit holders rather than to the government via a tax.

Figures 17.10 and 17.11 contain results from the G-cubed model of a tax of US $\$ 10$ (in 2002 constant prices) per tonne of carbon, for the United States and China. Results are shown from 2007 to 2055. The short-term response of emissions in China is much larger than in the United States. The initial price of energy in China is much lower than in the United States so the tax (on a per unit basis) causes a much larger proportional rise in the price of carbon-intensive energy in China than in the United States. The response in the short term reflects substitution and conservation by households and industry as well as a significant contraction in economic activity in China relative to the baseline. GDP falls by 0.9 per cent relative to the baseline in the initial year, compared with 0.2 per cent in the United States. Over time, substitution in production and the use of energy allows a larger carbon reduction with less impact on GDP. GDP initially falls in both countries and in the longer term it is higher in China due to efficiency gains from more efficient use of

Figure 17.8 Projection of Chinese carbon emissions, 2002-2026

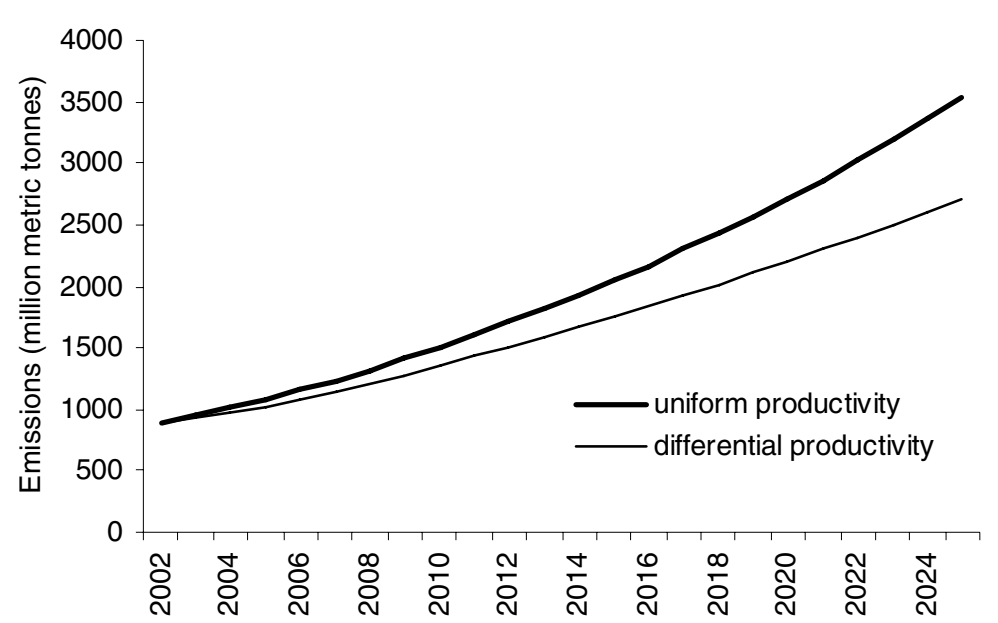

Source: G-cubed model version 63E. 
Figure 17.9 Projection of Chinese real GDP growth, 2002-2026 (per cent per annum)

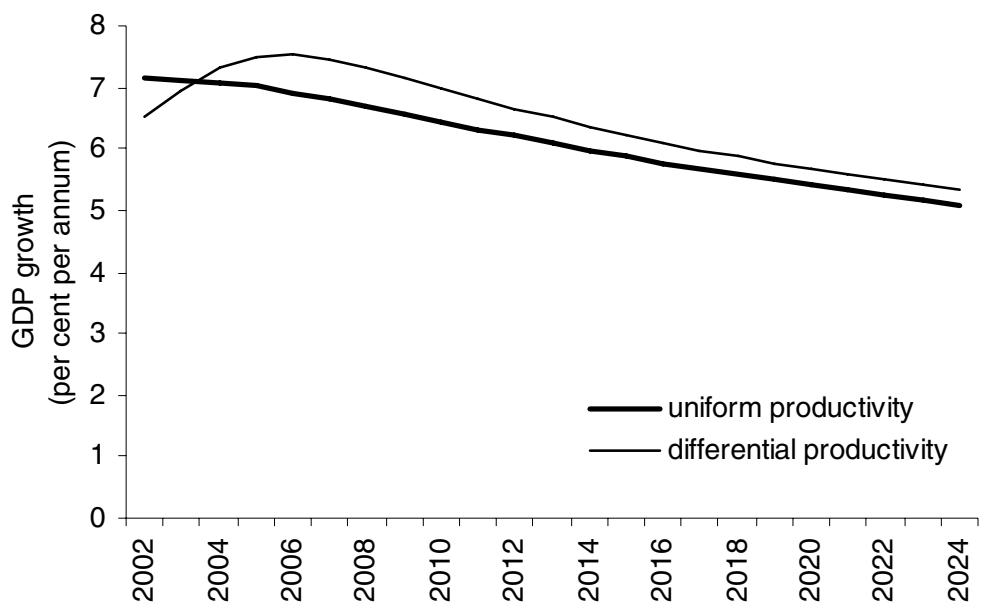

Source: G-cubed model version 63E.

energy. These results indicate that in the G-cubed model energy prices-in particular, the price of carbon-are important in changing the future emissions profile.

\section{Conclusion}

China currently faces a number of important problems related to energy use. At the forefront is the issue of how to deal with the desire for sustained economic growth at the same time as tackling serious environmental issues caused by energy generation. This issue is likely to become more important in coming years, especially as energy demand soars, environmental problems worsen and incomes rise. It is likely, under current global energy price structures, that future energy in China will be generated largely by the use of coal. Under current technologies in China, this is likely to have serious environmental consequences. Current plans to increase the use of nuclear and renewable energy such as hydroelectric and wind power are impressive but will likely have little impact in a rapidly expanding energy sector unless there is a significant change in the expected relative price of carbon. Other technologies-such as carbon sequestration, which is showing great potential-are also an option, although this technology will be more economically viable more quickly with a change in Chinese and global carbon prices. 
For some time, China has been taking action on local environmental issues. This has been particularly true in dealing with air and water quality as well as sulphur dioxide emissions. Action is already under way to reduce emissions of sulphur dioxide by moving away from high-sulphur coal, by closing small, highsulphur coalmines, with direct controls on sulphur dioxide emissions, implementation of pilot schemes for sulphur dioxide emission charges and pilot schemes for sulphur dioxide emissions trading. These are having an impact on emissions of sulphur, although the impact on acid rain in China and across Northeast Asia has been less clear. ${ }^{15}$

I have argued (McKibbin 2006a) that black carbon and its direct health, economic and environmental consequences are promising areas for close attention and direct policy intervention within China. This is not an issue of technological change at the power utilities as might usually be the focus of energy policy. A reduction in the emissions of black carbon will require a technology shift in the way households generate energy for heating and cooking and in the way farmers clear their land after harvest. Black carbon is a good candidate for consideration under the Asia Pacific Partnership for Clean Development and Climate (APPCDC) announced on 28 July 2005, which includes the United States, Japan, Australia, South Korea, China and India.

A critical issue facing China and the global community directly related to energy use in China is the emission of carbon dioxide. China and most other countries are yet to take effective action on reducing greenhouse gas emissions. Even if rapid action were possible, the lags between emissions and climate change are so long that benefits are unlikely for many decades. Although some researchers believe that global responses, such as through the CDM in the Kyoto Protocol, are a way to proceed, ${ }^{16}$ it is doubtful that much can be achieved through this approach alone. A strong case can be made for responses to be developed within China, Korea, Japan and other economies in the Asia Pacific region for dealing with carbon dioxide emissions. This has already begun to emerge within the APPCDC. The current idea within this group of countries of technology transfer without a carbon price signal is unlikely to be as effective as a way forward as a system based on clear long-term price signals that give incentives for reducing carbon dioxide emissions. One estimate of the sensitivity of carbon emissions to price changes has been presented in this paper. Within the APPCDC framework, there is potential to experiment with hybrid market-government control schemes such as the McKibbin-Wilcoxen blueprint, in which important institutions are created to begin a long process of reduced carbonisation of the Chinese economy. This would allow China to continue to grow but would put in place a pricing mechanism for future carbon emissions as an 
Figure 17.10 Response of emissions to a carbon tax in each country, 20072058 (US\$10 per tonne of carbon)

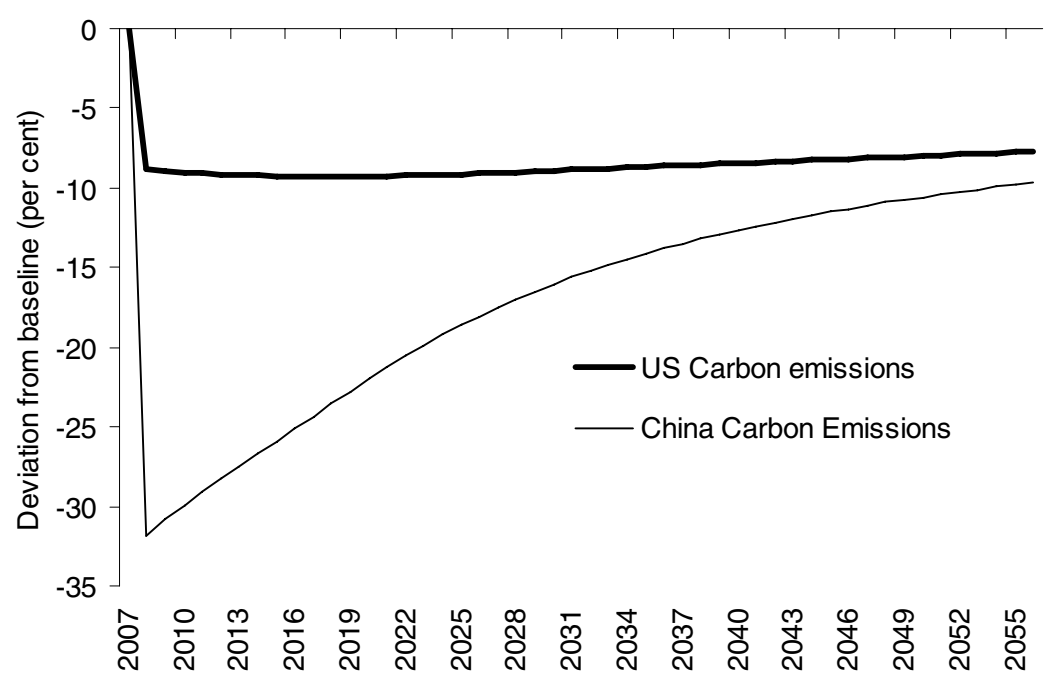

Source: G-cubed model version 63E.

Figure 17.11 Response of GDP to a carbon tax in each country, 2007-2055 (US\$10 per tonne of carbon)

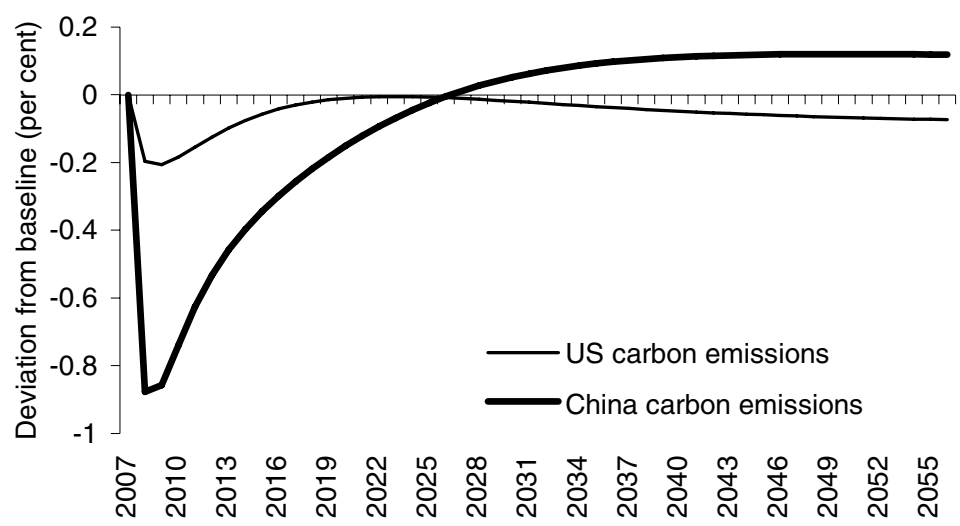

Source: G-cubed model version 63E. 
incentive to shift Chinese energy systems gradually to low carbon-emitting technologies. The creation of institutions for environmental management based on market incentives together with appropriate pricing of consequences of current energy generation technologies are important for long-range energy planning in China.

China and other countries in the Asia Pacific region are at a critical juncture in determining the nature of energy use in the global economy and the potential global environmental impact of a rapidly growing China. Addressing this problem effectively is not easy, as shown by the reality that many of the potential solutions to environmental problems related to energy use are not yet implemented in other Asia Pacific economies. The form of future energy systems and the problem of reducing global carbon dioxide emissions cannot be resolved seriously without the complete participation of China in any strategies. But these strategies need to be determined domestically within a framework of multilateral cooperation rather than being imposed from the outside. The preliminary results in this chapter suggest that, given appropriate use of markets and pricing energy -in particular, carbon pricing —China can sustain high economic growth with less environmental damage from energy use and a smaller contribution to global carbon dioxide emissions than an extrapolation of recent trends would predict.

\section{Acknowledgments}

This chapter extends earlier research funded by the China Economic Research and Advisory Program (CERAP). The author thanks Yan Yang for excellent research assistance. The views expressed in the paper are those of the author and should not be interpreted as reflecting the views of the institutions with which the author is affiliated, including the trustees, officers or other staff of the ANU, the Lowy Institute and the Brookings Institution.

\section{Notes}

1 All data, unless specifically indicated otherwise, are sourced from Energy Information Agency, 2006b. International Energy Outlook 2006, Department of Energy, Washington DC.

2 These issues are discussed more extensively in McKibbin 2006. See also China Council for International Cooperation on Environment and Development 2001; Panayotou and Zheng 2000; Streets 2004; and Wang and Smith 1999.

3 See Jiang 2002; and Zhang 1998.

${ }^{4}$ There are many other environmental problems in China caused by a large population and rapid economic growth, such as water and air quality problems caused by deforestation and desertification. China's demand for resources also has a large impact on the environment of other countries. These important problems are not the subject of this paper, but for an overview see Liu and Diamond 2005.

5 China's Environmental Protection Law was promulgated in 1979 - a nationwide levy system on 


\section{The Turning Point in China's Economic Development}

pollution began in 1982. The collection of fees for sulphur dioxide pollution from coal began in 1992. See Jiang 2003 for an overview.

6 See Jiang 2003; and Panayatou 1998 for an overview of China's environmental problems.

2004 UNDP Human Development Report.

DOE 2005.

9 See National Bureau of Statistics of China, China Statistical Yearbooks for 1990-2005.

10 See McKibbin and Wilcoxen 2002 for a summary of the negotiations and critique of the approach.

${ }^{11}$ Earlier estimates of the cost of Kyoto can be found in Weyant 1999. Direct comparisons of the COP3 and COP7 versions of the protocol can be found in Bohringer 2001; Buchner et al. 2001; Kemfert 2001; Löschel and Zhang 2002; and McKibbin and Wilcoxen 2004.

12 See Intergovernmental Panel on Climate Change 2001.

${ }^{13}$ See McKibbin and Wilcoxen 2002a for a survey; and Pezzey 2003 for a comparison of taxes and permits.

${ }_{14}$ See McKibbin and Wilcoxen 1998, and documentation at http://www.gcubed.com

${ }_{15}$ Nakada and Ueta 2004 point out that there are likely to be gains for other economies in the region, such as Japan and Korea, to cooperate with China in controlling sulphur emissions since these economies are also directly affected by acid rain emanating from China.

${ }^{16}$ See Ueta et al. 2005.

17 Full details of the model, including a list of equations and parameters, can be found online at www.gcubed.com

${ }_{18}$ These issues include: Reaganomics in the 1980s; German reunification in the early 1990s; fiscal consolidation in Europe in the mid 1990s; the formation of the North American Free Trade Agreement (NAFTA); the East Asian financial crisis; and the productivity boom in the United States.

${ }_{19}$ See Blanchard and Fischer 1989; and Obstfeld and Rogoff 1996. 


\section{Appendix 17.1: the G-cubed model for projecting energy use and greenhouse emissions in China}

The G-Cubed model is an intertemporal general equilibrium model of the world economy. The theoretical structure is outlined in McKibbin and Wilcoxen (1998). ${ }^{17}$ A number of studies_summarised in McKibbin and Vines (2000)—show that the G-cubed modelling approach has been useful in assessing a range of issues across a number of countries since the mid $1980 \mathrm{~s} .{ }^{18}$ Some of the principal features of the model are as follows.

The model is based on explicit intertemporal optimisation by the agents (consumers and firms) in each economy. ${ }^{19}$ In contrast with static CGE models, time and dynamics are of fundamental importance in the G-cubed model. The MSG-cubed model is known as a Dynamic Stochastic General Equilibrium (DSGE) model in the macroeconomics literature and as a Dynamic Intertemporal General Equilibrium (DIGE) model in the computable general equilibrium literature.

In order to track the macro time series, the behaviour of agents is modified to allow for short-term deviations from optimal behaviour due either to myopia or to restrictions on the ability of households and firms to borrow at the risk-free bond rate on government debt. For households and firms, deviations from intertemporal optimising behaviour take the form of rules of thumb, which are consistent with an optimising agent that does not update predictions based on new information about future events. These rules of thumb are chosen to generate the same steadystate behaviour as optimising agents so that in the long term there is only a single intertemporal optimising equilibrium of the model. In the short term, behaviour is assumed to be a weighted average of the optimising and the rule-of-thumb assumptions. Therefore, aggregate consumption is a weighted average of consumption based on wealth (current asset valuation and expected future aftertax labour income) and consumption based on current disposable income. Similarly, aggregate investment is a weighted average of investment based on Tobin's ' $q$ ' (a market valuation of the expected future change in the marginal product of capital relative to the cost) and investment based on a backward-looking version of ' $Q$ '.

There is an explicit treatment of the holding of financial assets, including money. Money is introduced into the model through a restriction that households require money to purchase goods.

The model also allows for short-term nominal wage rigidity (by different degrees in different countries) and therefore allows for significant periods of unemployment depending on the labour-market institutions in each country. This assumption, when taken together with the explicit role for money, is what gives the model its 
macroeconomic characteristics. (Here again, the model's assumptions differ from the standard market-clearing assumption in most CGE models.)

The model distinguishes between the stickiness of physical capital within sectors and within countries and the flexibility of financial capital, which immediately flows to where expected returns are highest. This important distinction leads to a critical difference between the quantity of physical capital that is available at any time to produce goods and services, and the valuation of that capital as a result of decisions about the allocation of financial capital.

As a result of this structure, the G-cubed model contains rich dynamic behaviour, driven on the one hand by asset accumulation and, on the other, by wage adjustment to a neoclassical steady state. It embodies a wide range of assumptions about individual behaviour and empirical regularities in a general equilibrium framework. The interdependencies are solved using a computer algorithm that solves the rational expectations of equilibrium of the global economy. It is important to stress that the term 'general equilibrium' is used to signify that as many interactions as possible are captured, not that all economies are in a full market-clearing equilibrium at each point in time. Although it is assumed that market forces eventually drive the world economy to a neoclassical steady-state growth equilibrium, unemployment does emerge for long periods due to wage stickiness, to an extent that differs between countries due to differences in labour-market institutions. 
Appendix Table A17.1 Overview of the G-cubed model (version 63E)

\section{Regions}

United States

Japan

Australia

Europe

Rest of the OECD

China

Oil-exporting developing countries

Eastern Europe and the former Soviet

Union

Sectors

Energy:

Other developing countries

Electric utilities

Gas utilities

Petroleum refining

Coalmining

Crude oil and gas extraction

Non-energy:

Mining

Agriculture, fishing and hunting

Forestry/timber products

Durable manufacturing

Non-durable manufacturing

Transportation

Services Capital-producing sector 